\title{
Juvenile trabecular ossifying fibroma of the mandible
}

Received: 19 December 2009 / Accepted: 11 February 2010

(C) Association of Oral and Maxillofacial Surgeons of India 2009

Abstract Juvenile Ossifying Fibroma (JOF) is a rare fibro-osseus neoplasm in young children. This lesion is locally aggressive and spreads quickly. It is usually asymptomatic, achieving a large size. Owing to its aggressive behavior and high recurrence rate, early detection and complete surgical excision are essential. This report details the diagnosis and treatment of a 3-year-old girl presenting with a mandibular swelling that was subsequently determined to be juvenile ossifying fibroma.

Keywords Juvenile ossifying fibroma $\cdot$ Trabecular $\cdot$ Mandible $\cdot$ Neoplasm

\section{Introduction}

The term juvenile ossifying fibroma is used in naming two microscopically distinct fibro-osseous lesion of the craniofacial skeleton.

Psammomatoid Juvenile Ossifying Fibroma (PSJOF) characterized by small uniform spherical ossicles resembling psammoma bodies. Trabacular Juvenile Ossifying Fibroma (Tr JOF) distinguished by trabaculae of fibrillary osteoid and woven bone.

Psammomatoid Juvenile Ossifying Fibroma (PSJOF) is reported more commonly than Trabacular Juvenile Ossifying Fibroma. It affects patients from wide age range (3 months -72 years) and an older mean age range (16-33 years) as compared with 2-12 years and $8 \frac{1}{2}-12$ years respectively for Trabacular Juvenile Ossifying Fibroma [3]. There is a slight male predilection in both types. A significant difference between the two tumours is their site of occurrence. Psammomatoid Juvenile Ossifying Fibroma (PSJOF) occurs predominantly in the sinonasal and orbital bones, Trabacular Juvenile Ossifying Fibroma predominantly affects the jaws. Aggressive growth occurs in some cases of both the types.

\section{Case report}

A 3-year-old female child patient was referred to the Department of Oral and

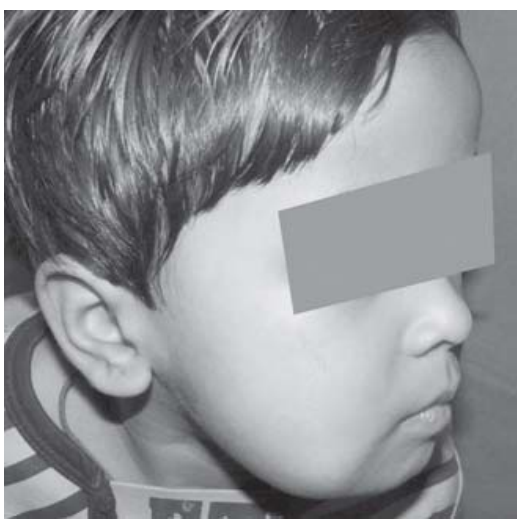

Fig. 1 Profile view of the lesion

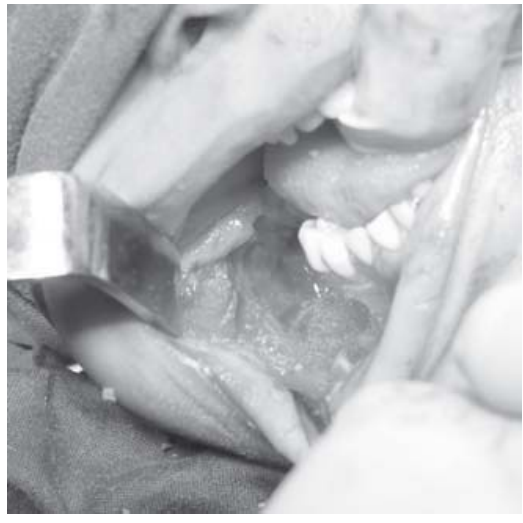

Fig. 3 Intraoperative photograph

Maxillofacial Surgery. The patients parents were aware of the right facial swelling over a period of 8 months. The lesion had been

\author{
Khurshida Banu ${ }^{1} \varangle \cdot$ Suresh Menon \\ Palikat $^{2}$ \\ ${ }^{1}$ Professor and Head \\ ${ }^{2}$ Associate Professor
}

Dept. of Oral and Maxillofacial Surgery, Vydehi Institute of Dental Sciences and Research Center, Bangalore

Address for correspondence:

\section{Khurshida Banu}

Dept. of Oral and Maxillofacial Surgery Vydehi Institute of Dental Sciences and Research Center,

No. 82, EPIP Area, Whitefield,

Bangalore, Karnataka, India

E-mail: abdarakib@yahoo.co.in

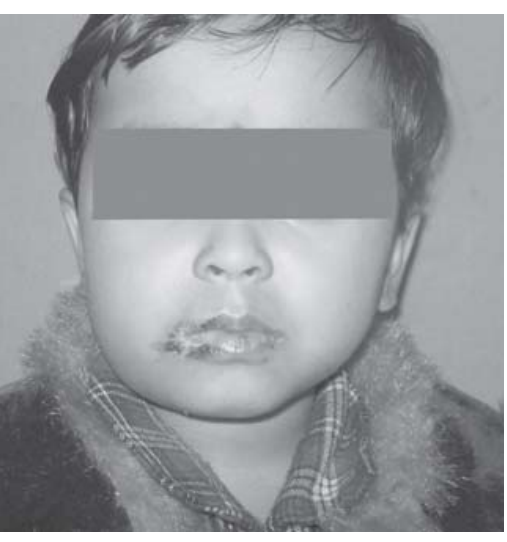

Fig. 2 Postoperative extra-oral front view

slowly increasing in size since it was noticed. There was no history of trauma, pain, paresis, paresthesia, lymphadenopathy or dysphagia. Physical examination showed a healthy, normal developed young girl with no apparent distress. There was significant facial asymmetry on the right side of the face. Intra-oral examination revealed an approximately $5 \times 5 \mathrm{~cm}$ mass in the molar, premolar region. The mass was firm and non tender to palpation and not adherent to the overlying skin. There was expansion of buccal cortex and inferior border of mandible. There was no evidence of tooth mobility, abscess formation, dehiscence or malocclusion. Examination of the neck found no abnormalities. A panoramic radiograph revealed a well-circumscribed 
radiolucency with faint linear to irregular central opacities. The tooth bud of right mandibular first molar was present. The roots of mandibular right first and second molar were found to be resorbed. Expansion and thinning of the lateral and inferior cortex, and central calcification was evident. A FNAC - Fine needle aspiration of the involved area did not yield fluid. Laboratory values were within normal limits except for a slight increase in Alkaline Phosphatase (ALP).

The lesion was excised under general anesthesia through an intra-oral degloving incision. Inspection of the bony cavity showed no cortical dehiscence. Microscopic examination showed a cellular connective tissue consisting of fibroblasts arranged in a whorled pattern which merged into anastomosing areas of cellular condensation. There were ribbon like osteoid trabeculae lined by plump osteoblasts that showed a transition into areas of woven bone associated with occasional osteoclasts. Clusters of multinucleated giant cells were noted near areas of stromal hemorrhage. Periphery of vital bone was separated by a thick fibrous connective tissue. Based on clinical history and the radiographic and histologic features of the lesion, a diagnosis of Juvenile Ossifying Fibroma Trabecular type was established. The patient was discharged from the hospital and has since been on follow-up, with no evidence of recurrent disease after 8 months.

\section{Discussion}

The term Ossifying Fibroma has been used to describe clinically and microscopically heterogenous lesions of the skull [15]. Juvenile Ossifying Fibroma is used in the literature to describe 2 distinct histopathologic variants of ossifying fibroma of the craniofacial skeleton [1,2]. These are referred to as Psammomatoid Juvenile Ossifying Fibroma (PsJOF) and Trabecular Juvenile Ossifying Fibroma (TrJOF) [3,4]. Although Juvenile Ossifying Fibroma can occur anywhere in the skeleton, its highest incidence is in the facial bones. Most commonly the maxilla [4]. Mandibular and extra cranial involvement are rare $[5,6,8,10,11,12,20]$.

Table 1 summarizes the three clinic pathologic variants of ossifying fibroma with their key features.

Trabecular Juvenile Ossifying Fibroma is characterized by a progressive and

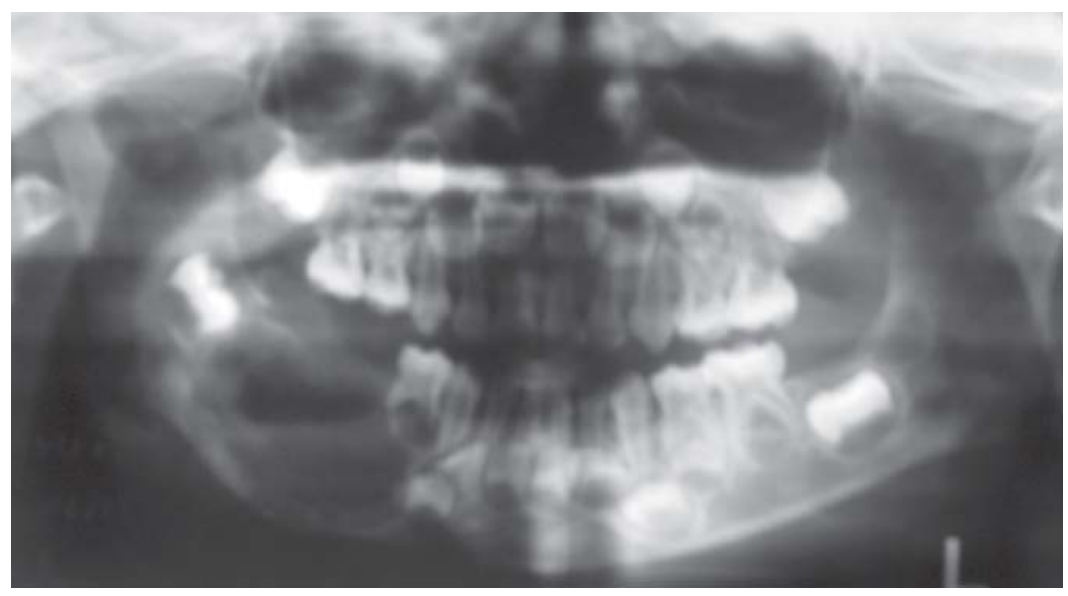

Fig. 4 OPG showing mixed radiopaque and radiolucent lesion

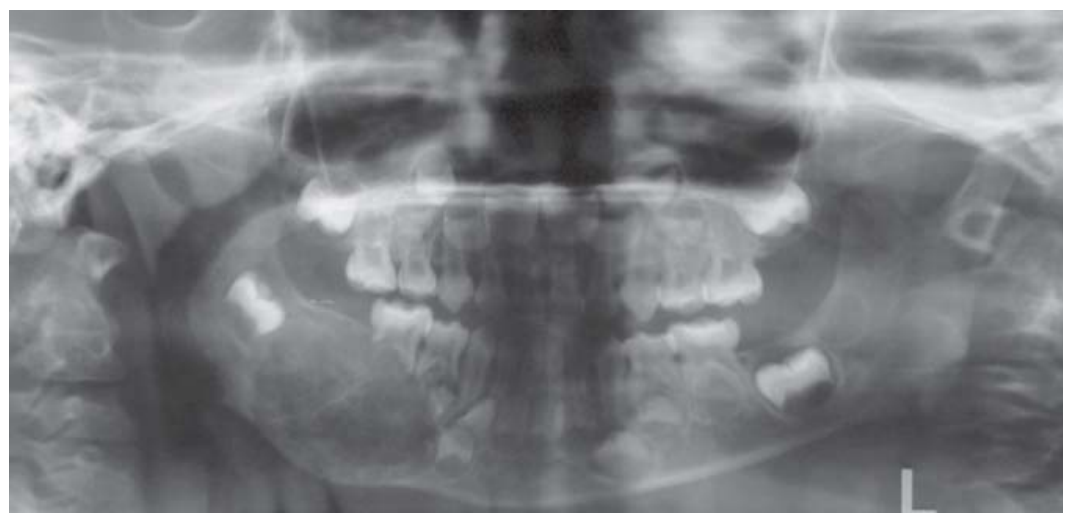

Fig. 5 OPG showing immediate postoperative

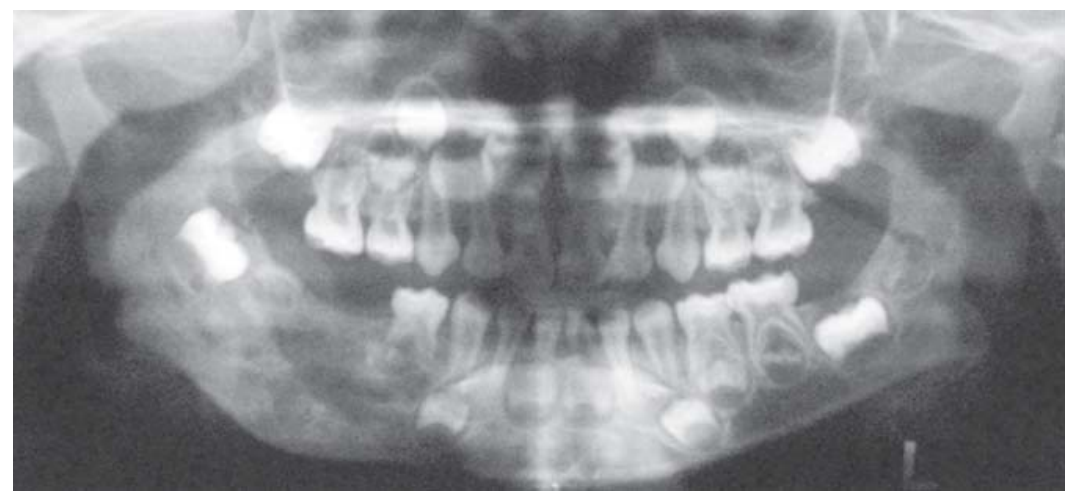

Fig. 6 Postoperative OPG after 10 months

sometimes rapid aggressive growth [3,4]. The tumour expands the affected bone leading to facial asymmetry.

Radiographically, it is expansive, well defined unilocular or multilocular with cortical thinning and perforation $[5,6,7]$. The tumour mass is radiolucent with variable calcification - Induced Radio opacities. Occasionally producing a 'Ground Glass' appearance [8]. Root resorption and displacement of involved teeth are observed. In the mandible the angle and ramus are more commonly involved [5,9]. Trabecular Juvenile Ossifying Fibroma is not encapsulated, but is separated from surrounding bone by a radiopaque border, and this finding can help in differentiation from fibrous dysplasia [7,8,17].

Microscopic examination of Trabecular Juvenile Ossifying Fibroma shows a well defined but unencapsulated lesion that infiltrates surrounding bone $[15,16,17]$. The tumour is composed of cell-rich fibroblastic spindle cell stroma. Fibrillary osteoid matrix 
Table 1 Summarizes the three clinic pathologic variants of ossifying fibroma with their key features

\begin{tabular}{|c|c|c|c|c|}
\hline & Ossifying fibroma & Juvenile trabecular ossifying fibroma & \multicolumn{2}{|c|}{$\begin{array}{c}\text { Juvenile psammomatoid ossifying } \\
\text { fibroma } \\
\end{array}$} \\
\hline Age (mean) & $10-50$ years $(35)$ & $2-30$ years $(10)$ & \multicolumn{2}{|c|}{3 months -72 years $(20)$} \\
\hline Female:Male & $2: 1$ & $1.2: 1$ & $1.3: 1$ & \\
\hline \multirow[t]{3}{*}{ Site } & Tooth-bearing areas & Mandible $\quad 50 \%$ & Sinonasal & $62 \%$ \\
\hline & Mandible $\quad 70 \%$ & Maxilla & Maxilla & $20 \%$ \\
\hline & Maxilla $\quad 30 \%$ & Sinonasal $\quad 6 \%$ & $\begin{array}{l}\text { Mandible (ramus) } \\
\text { Cranium }\end{array}$ & $\begin{array}{c}10 \% \\
8 \%\end{array}$ \\
\hline \multirow[t]{2}{*}{ Radiology } & $\begin{array}{l}\text { Well circumscribed } \\
\text { Unilocular }\end{array}$ & Well circumscribed & \multicolumn{2}{|l|}{ Well circumscribed } \\
\hline & Variable radiopacity & Speckled calcifications & \multicolumn{2}{|c|}{$\begin{array}{l}\text { Expands and fills paranasal } \\
\text { sinuses - 'aggressive pattern' } \\
\text { tends to be radiopaque }\end{array}$} \\
\hline Histopathology & $\begin{array}{l}\text { Cellular fibrous tissue, } \\
\text { storiform pattern, } \\
\text { separate trabeculae } \\
\text { of woven bone, } \\
\text { occasional spherical, } \\
\text { psammomatoid } \\
\text { calcifications, } \\
\text { encapsulated }\end{array}$ & $\begin{array}{l}\text { Densely cellular, immature osteoid and } \\
\text { in trabecular pattern, osteoblast rimming } \\
\text { and cellular osteoid }\end{array}$ & \multicolumn{2}{|c|}{$\begin{array}{l}\text { Densely cellular, spherical cementum- } \\
\text { like psammomatoid calcifications, may } \\
\text { permeate cancellous bone, myoid areas, } \\
\text { giant cells, haemorrhage }\end{array}$} \\
\hline \multirow[t]{3}{*}{ Synonyms } & $\begin{array}{l}\text { Cemento-ossifying } \\
\text { fibroma }\end{array}$ & Juvenile aggressive ossifiyng fibroma & \multicolumn{2}{|c|}{ Cemento-ossifying fibroma } \\
\hline & Cementifying fibroma & Juvenile ossifying fibroma WHO type & \multirow{2}{*}{\multicolumn{2}{|c|}{$\begin{array}{l}\text { Juvenile ossfying fibroma with } \\
\text { psammomatoid ossicles } \\
\text { Juvenile ossfying fibroma psammous } \\
\text { desoosteoblastoma }\end{array}$}} \\
\hline & Periodontoma & Trabecular desoosteoblastoma & & \\
\hline
\end{tabular}

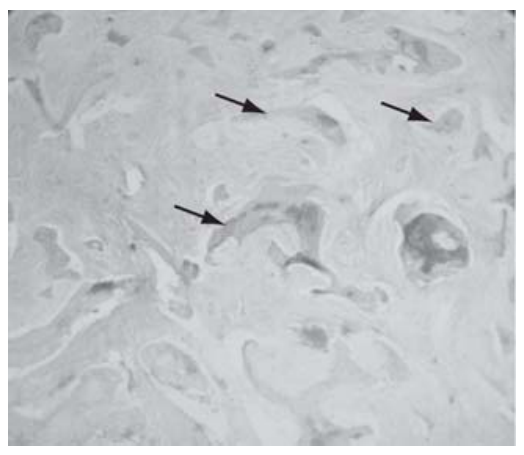

$\mathrm{H} \& \mathrm{E}$ picture of the lesion at $10 \mathrm{x}$ view arrows indicating the immature trabeculae of bone

develops incorporating plump eosinophilic osteoblastic cells. Progressive calcification of the osteoid results in anastomosing trabeculae of immature woven bone and focal collections of multinucleated giant cells are not seen. Not all cases show a fast and aggressive growth rate [5,6]. Surgical excision is the recommended treatment for Trabecular Juvenile Ossifying Fibroma

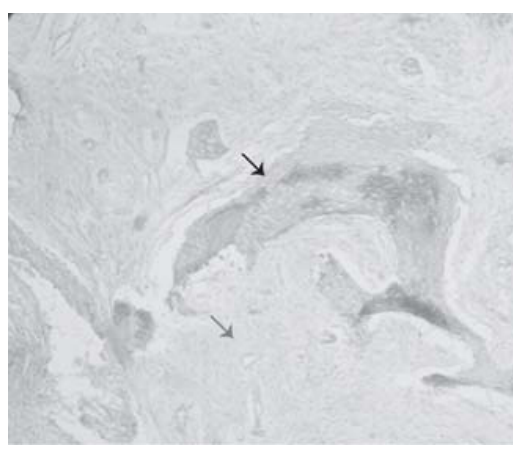

H\&E picture of the lesion at $40 \mathrm{x}$ view with black arrow indicating the immature trabeculae of bone and light black arrow indicating the cellular connective tissue

$[6,9]$. Because of infiltrating borders, the tumour cannot be shelled out but should be conservatively excised entirely. Recurrences are seen in $30 \%$ to $58 \%[2,7,10]$ of cases. More than one excision may be required to achieve a cure [7]. No malignant transformation has been reported and radical surgical procedures are not necessary $[3,6]$ which corroborates with the treatment provided in the present case. The age of the child and the growth considerations also mitigated against a radical surgical approach.

\section{Conclusion}

The incidence of JOF is still unknown because of the relatively few cases reported till date. In the case discussed here, clinical, radiological and histological features confirmed the diagnosis of JOF.

The clinical management of JOF remains uncertain. Small lesions can be treated conservatively by curettage or enucleation $[3,7]$ and follow-up for a prolonged period of time is recommended [5] as there is high rate of recurrence of these tumours as described in the literature $[3,4,7]$.

\section{References}

1. Waldron CA (1993) Fibro-osseous lesions of the jaws. J Oral Maxillofac Surg 51(8): 828-835 
2. Slootweg PJ, Panders AK, Koopmans R, Nikkels PG (1994) Juvenile ossifying fibroma. An analysis of 33 cases with emphasis on histopathological aspects. J Oral Pathol Med 23(9): 385-388

3. El-Mofty S (2002) Psammomatoid and Trabecular Juvenile ossifying fibroma of the craniofacial skeleton. Two distinct clinico pathologic entities. Oral Surg Oral Med Oral Pathol Oral Radiol Endod 93(3): 296-304

4. Johnson LC, Yousefi M, Vinh TN, Heffner DK, Hyams VJ, Hartman KS (1991) Juvenile active ossifying fibroma. Its nature, dynamics and origin. Acta Otolaryngol Suppl 488: $1-40$

5. Noffke CEE (1998) Juvenile ossifying fibroma of the mandible. An 8 year radiological follow-up. Dentomaxillofac Radiol 27(6): 363-366

6. Rinaggio J, Land M, Cleveland DB (2003) Juvenile Ossifying Fibroma of the mandible. J Pediatric Surg 38(4): 648-650

7. Shekhar MG, Bokhari K (2009) Juvenile Aggressive Ossifying Fibroma of the Maxilla. J Indian Soc Pedod Prev Dent 27(3): 172-174
8. Thankappan S, Nair S, Thomas V, Sharafudeen KP (2009) Psammomatoid and Trabecular variants of Juvenile Ossifying Fibroma - 2 case reports. Indian J Radiol Imaging 19(2): 116-119

9. Gardner JA, Hanft RJ (1960) An Ossifying Fibroma of the mandible. Report of a case. Oral Surg Oral Med Oral Pathol 13: 1288-1294

10. Slootweg PJ, Moller H (1990) Juvenile Ossifying Fibroma. Report of 4 cases. J Craniomaxillofac Surg 18(3): 125-129

11. Halkias LE, Larsen PE, Allen CM, Steinberg MJ (1998) Rapidly growing, Expansive mass of the Mandible in a 6 year old boy. J Oral Maxillofac Surg 56(7): 866-871

12. Sciubba JJ, Younai F (1989) Ossifying Fibroma of the mandible and maxilla. Review of 18 cases. J Oral Pathol Med 18(6): 315-321

13. Makek MS (1987) So called 'Fibro Osseous Lesions' of Tumourous origin. Biology confronts terminology. J Craniomaxillofac Surg 15(3): 154-167

14. Slootweg PJ (1996) Maxillofacial Fibro-Osseous lesions, Classification and differential diagnosis. Semin Diagn Pathol 13(2): 104-112
15. Pefer A, Reichart / Hans P. philipsen Odontogenic Tumours and allied lesion. 2004 - Q.P. London. EDS 278 279

16. Waldron CA Bone Pathology. In : Neville BW, Damm DD, Allen CM, Bouquot JE, Editors (1995) Oral and maxillofacial Pathology Philadelphia: WB Saunders 443-492

17. Williams HK, Mangham C, Speight PM (2000) Juvenile Ossifying Fibroma; An analysis of Eight cases and a comparison with other Fibro-Osseous lesions. J Oral Pathol Med 29(1): 13-18

18. Zama M, Gallo S, Santecchia L, Bertozzi E, DE Stefano C (2004) Juvenile Active Ossifying Fibroma with massive involvement of the mandible. Plast reconstr Surg 113(3): 970-974

19. Saiz-Pardo-Pinos AJ, Olmedo-Gaya MV, Prados-Sanchez E, VallecilloCapilla M (2004) Juvenile Ossifying Fibroma: A case study. Med Oral Pathol Oral Cir Bucal 9(5): 456-458

20. Paul M Speight, Roman Carlos, Current Diagnostic Pathology 2006, issue 12, page 1-10, Mini Symposium, Head \& Neck Pathology, Maxillofacial, Fibro Osseous Lesions

Source of Support: Nil, Conflict of interest: None declared. 